\title{
Coulisses
}

Revue de théâtre

15 | Hiver 1997

Varia

\section{Comme des flèches de Koulsy Lamko}

\section{Marcel K. Djondo}

\section{CpenEdition}

Journals

Édition électronique

URL : http://journals.openedition.org/coulisses/5005

DOI : $10.4000 /$ coulisses. 5005

ISSN : 2546-9460

\section{Éditeur}

Presses universitaires de Franche-Comté

\section{Édition imprimée}

Date de publication : 1 janvier 1997

Pagination : $19-20$

ISSN : 1150-594X

\section{Référence électronique}

Marcel K. Djondo, «Comme des flèches de Koulsy Lamko », Coulisses [En ligne], 15 | Hiver 1997, mis en ligne le 26 avril 2019, consulté le 24 octobre 2019. URL : http://journals.openedition.org/coulisses/ 5005 ; DOI : 10.4000/coulisses.5005

Ce document a été généré automatiquement le 24 octobre 2019

Coulisses 


\title{
Comme des flèches ${ }^{1}$ de Koulsy Lamko
}

\author{
Marcel K. Djondo
}

Mise en scène de Amadou Bourou (Burkina Faso) et Denis Lepage (France) Salle Culturelle Fourier, Campus de la Bouloie, 12 Décembre 1996 à 21h Petit Kursaal, 17 Décembre 1996 à 21h.

\section{L'auteur : Koulsy Lamko}

1 Auteur de plusieurs textes dramatiques, contes et nouvelles, Koulsy Lamko, né au Tchad, a créé en 1994 au Burkina Faso Kaleido Culture, agence d'animation culturelle de projet. Il prépare également une thèse de doctorat sur les nouvelles esthétiques théâtrales en Afrique Noire Francophone.

2 Ses textes Ndo Kela ou l'initiation avortée et Tout bas... Si bas! ont été mis en espace aux $10^{\mathrm{e}}$ et $12^{\mathrm{e}}$ Festivals Internationaux des Francophonies en Limousin par Jean Claude Idée (Magasin d'écriture théâtrale).

Boursier de l'association Beaumarchais, il a été en résidence d'écriture au festival des Francophonies en 1992 et 1995.

\section{La Fable}

Cet après midi là, il n'y a pas eu d'oraison funèbre au cimetière, à l'enterrement de Bouba. Il y avait un goût d'inachevé qui se promenait sur toutes les langues. Et pourtant, dans cette région là, la mort était belle, elle était une fête. Bouleversée, Amina revoit défiler les temps forts de sa liaison avec le jeune mécanicien, victime du Sida et des exclusions. Aurait-elle maintenant la force de rompre le silence et d'annoncer à son mari qu'elle porte elle aussi la maladie?

\section{Le Spectacle}

Dans un décor qui se veut une réplique d'un petit atelier de vulcanisateur que l'on rencontre un peu partout au bord des rues en Afrique, les metteurs en scène ont su 
nous faire voyager entre vie et mort, espoir, désespoir, amour ou haine, bref entre rêve et réalité.

4 Le rêve est entretenu tout au long de la pièce par la poésie des mots, des gestes et surtout par la beauté des chansons. On se croirait dans un conte malgré l'acuité du sujet traité ; car les chansons dans la pièce jouent le même rôle que les « chansons internes " des contes africains, destinées à éclaircir une situation ou à délivrer un message important pour le dénouement.

5 La réalité est non seulement dans l'exactitude des gestes du vulcanisateur mais aussi dans le fait que le metteur en scène a préféré pour le rôle du griot, prendre des griots de métier et non des comédiens. Ce choix se justifie par le fait que sur un continent où tout ce qui touche à la sexualité est tabou, il faut avoir recours à des voix " autorisées " pour en parler. Tel est le cas de cette pièce où avec un jeu simple et un humour africain à la portée de tout public, les comédiens et griots ont su nous parler du Sida sans tomber dans la caricature.

6 Le scénario est très simple : « lui » est vulcanisateur, « elle » est institutrice. «Lui » est célibataire, « elle » est mariée et son mari ne la trouve plus à son goût. Elle vient faire réparer sa mobylette dans l'atelier. L'aventure commence... Quelque temps après, « lui » est malade du Sida.

7 Est-ce une contribution à la problématique de l'origine géographique du Sida ? À la culpabilité ou la non-culpabilité du malade? Le leitmotiv est: "on n'est jamais responsable d'être malade. C'est le corps qui n'a pas su se défendre ». Quoi qu'il en soit, le message de Koulsy est clair : il faut se dépêcher de rire de ses malheurs de peur d'en pleurer.

8 On pouvait sortir de ce spectacle le cœur léger, sans aucune sensation de culpabilité, ni de compassion, comme ce fut le cas du théâtre africain jusqu'à il y a seulement quelques années.

9 Le théâtre africain ce n'est pas du folklore. On ne doit pas l'aimer parce que c'est exotique. La démarche artistique des metteurs en scène s'inscrit dans un courant qui peut rivaliser avec tous les théâtres du monde par sa qualité et son authenticité. Outre cette exigence, le groupe a relevé le défi de réunir dans un seul projet les compétences de personnalités artistiques issues de différents pays africains: Tchad, Togo, BurkinaFaso. Cela est d'autant plus important qu'on connaît la somme de difficultés rencontrées dans ce genre d'entreprise, où les frontières entre les états se dressent implacables.

10 Koulsy Lamko, en tant que comédien, a fait un long chemin dans le théâtre de l'Opprimé et a travaillé avec Augusto Boal. L'écriture de Comme des flèches s'en ressent. La réalisation de ce spectacle s'inscrit dans un projet social dont l'objectif est d'arriver à sensibiliser le public sur le fléau du Sida. C'était donc un théâtre citoyen que nous ont proposé Amadou Bourou et Denis Lepage, ainsi que toute l'équipe sur le mode du conte moderne et de la poétique africaine. 


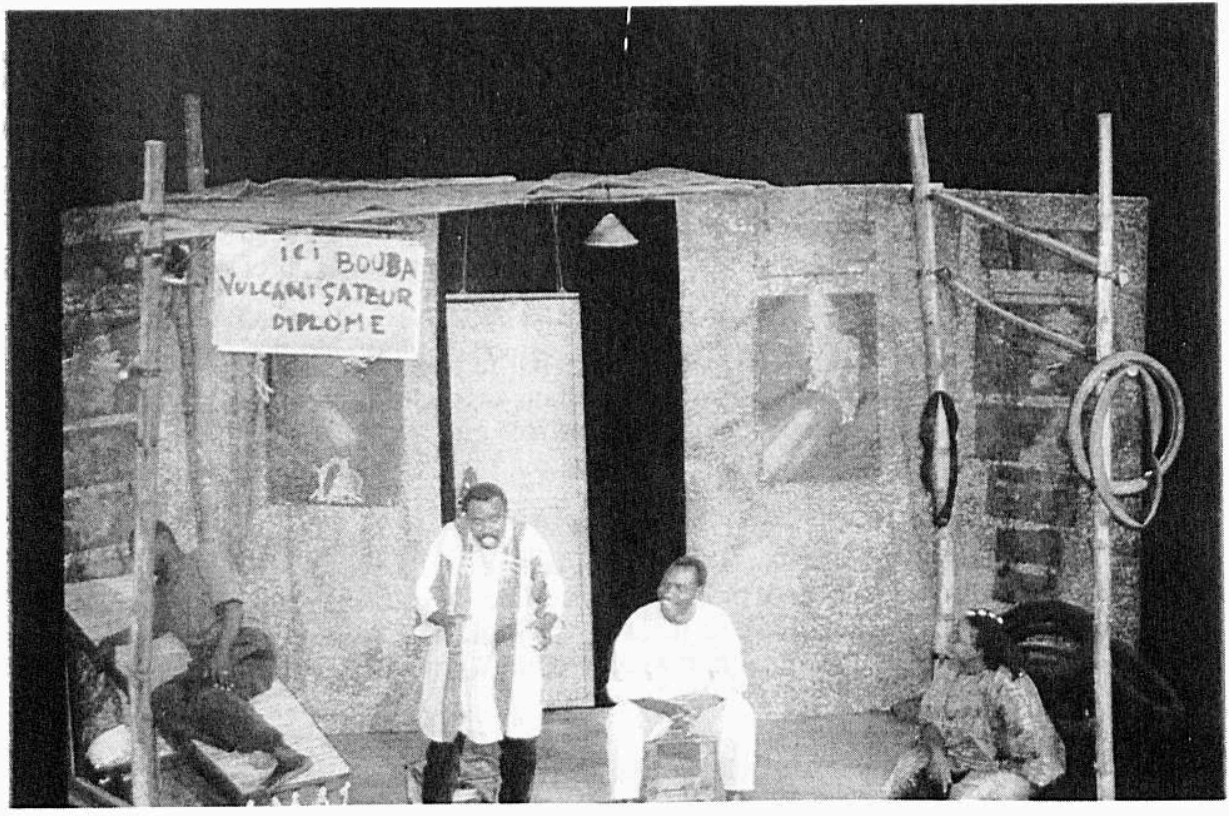

Cliché Kalëido Culture

\section{NOTES}

1. Ce texte a été écrit lors d'une résidence d'écriture Beaumarchais dans le cadre du $12^{\mathrm{e}}$ Festival des Francophonies en Limousin. Publié aux Editions Lansman - décembre 1996.

\section{AUTEURS}

\section{MARCEL K. DJONDO}

Comédien, animateur-metteur en scène du TUFC à Montbéliard 